\title{
Comparison of 3G and LTE with other Generation
}

\author{
Kanupriya Singh \\ Dept. of Computer Science \\ and Engineering \\ Amity University, Noida, India
}

\author{
Sanjeev Thakur \\ Dept.of Computer Science and \\ Engineering \\ Amity University, Noida, India
}

\author{
Somya Singh \\ Dept. of Computer Science \\ and Engineering \\ Amity University, Noida,India
}

\begin{abstract}
In this paper we give an overview of wireless mobiles, starting form first generation $(1 \mathrm{G})$ based on analogue system in 1980, while second generation (2G) which sets initial digital standards focuses on capacity and coverage. Emergence of GSM also belongs to 2G. After that third generation $(3 \mathrm{G})$ continues with the upgradation and adoption of new technologies such as UMTS-HSPA and CDMA200 EV-DO to provide high speed, low cost and bring the quality in services. Now Long Term Evolution (LTE)technology encompasses the pillars for next generation i.e. fourth generation $(4 \mathrm{G})$ for higher throughput, low latency mobile access, multicast and broadcast media and it sets standards for the deployment of $4 \mathrm{G}$ around the world.
\end{abstract}

This paper provides a view of these generations and gives a comparative study of $3 \mathrm{G}$ and LTE. It also provides some important issues and challenges related to LTE.

\section{General Terms}

Wireless communication, Mobile Broadband, mobile generations

\section{Keywords}

1G, 2G, 3G, LTE, 4G, UMTS

\section{INTRODUCTION}

Over the past two decades, there are exponential growths which have been recorded in the field of wireless communication and it going to continue due to the emergence of new interactive multimedia application. A key requirement in future wireless system is their ability to provide broadband connectivity with end to end quality of services (QOS), a high network capacity and throughput at low cost [2]. In last few years there have been clear shifts from fixed to mobile cellular telephony. By the end of 2010, there was four times more cellular subscription than fixed telephone line. Evolutions ofmobile network are crosses more than three generation.

Starting with first generation (in 1980's), based on analogue standards fulfills basic mobile voice (voice calls), moving towards second generation $(2 \mathrm{G})$ based on initial digital standards introduced the capacity and coverage, in 1990's. On the way to $3 \mathrm{G}$ there are many more designing scenarios that have deployed in between $2 \mathrm{G}$ and $3 \mathrm{G}$ like $2.5 \mathrm{G}$. $2.5 \mathrm{G}$ includes all advances upgrade to build $2 \mathrm{G}$ a stronger network [2]. $2.5 \mathrm{G}$ act as bridge between $2 \mathrm{G}$ and $3 \mathrm{G}$. $3 \mathrm{G}$ provides data at higher speeds to open the gate for truly "mobile broadband". $3 \mathrm{G}$ provides $144 \mathrm{kbps}$ of throughput at mobile speeds, $384 \mathrm{kbps}$ at pedestrian speeds and 2 mbps in indoor environment [1]. These requirements are specified by ITU. Now a days LTE (Long Term Evolution ) becoming the network technology for choice of $4 \mathrm{G}$ deployment around the world, it has the ability to provide very fast, highly responsive data services at low cost. LTE is the initial step taken for the coming generation i.e. fourth generation (4G).

\section{EVOLUTION OF GENERATIONS}

Electromagnetic waves were first discovered as a communication medium at the end of $19^{\text {th }}$ century. For offering mobile telephone services there are single cell systems which were constrained by restricted mobility, low capacity limited services and poor speech quality beside all these constraints, the equipment was heavy, bulky and expensive.

\subsection{First Generation (1G)}

In late 1970's and early 1980's the cellular era had started. First generation mobile system provides voice services based on analogue radio transmission techniques. The first cellular system in the world becomes operational by Nippon telephone and Telegraph (NTT) in Tokyo, Japan, in 1979. Semiconductor technology and microprocessor made smaller, lighter weight and more sophisticated mobile systems. The most popular analogue system was:

- $\quad$ Nordic Mobile Telephone (NMT):It was the first operational analogue system and was originally introduced into the Nordic countries of Denmark, Finland Sweden and Norway. NMT runs at 450 $\mathrm{MHz}$ and $900 \mathrm{MHz}$, some NMT-450 are still operational but NMT-900 has been closed.

- Advanced Mobile Phone System (AMPS):It was launched in 1982 and first has been in operation in North and Latin America. It allocates $40 \mathrm{MHz}$ bandwidth within the 800 to $900 \mathrm{MHz}$ frequency range. Omnidirectional antennas were used in the earlier AMPS implementation then it switched to directional antennas which would yield better cell reuse i.e. 7-cell reuse pattern was adopted for AMPS. AMPS uses frequency division multiple access (FDMA) technology.

- $\quad$ Total Access Communication System (TACS):It was derived from AMPS and was introduced as analogue standards for UK. It operates on $900 \mathrm{MHz}$ in UK and 800-900 MHz in China and Japan.

- Cellular Digital Packet Data (CDPD): It makes use of excess capacity on the Amps network to provide packetized connection up to $19.2 \mathrm{kbps}$, inherent data overheads reduce this to a practical operating data rate of around $10 \mathrm{kbps}$.

AMPS and TACS uses the frequency was the frequency modulation (FM) technique for radio transmission. 1G uses FDMA and circuit switched technologies in the network core. All these systems offer handover and roaming capabilities but 
the cellular networks were unable to interoperate between countries. This was one of the important disadvantages of $1 \mathrm{G}$ mobile network.

\subsection{Second Generation (2G)}

Second generation $(2 \mathrm{G})$ was come into existence at the end of 1980 's. It supports low bit rate data services as well as traditional speech services. 2G uses Time Division Multiple Access (TDMA) and Code Division Multiple Access (CDMA) technology. As compared with $1 \mathrm{G}$ it provides higher spectrum efficiency, better data service and more advance roaming facilities. Three primary benefits of $2 \mathrm{G}$ networks were

- $\quad$ phone conversation were digitally encrypted

- more efficient to offer wider spectrum

- Introduce data services for mobile starting with SMS (short message service) and also serve as battery saver.

To provide a single unified standard the scenario of Global System for Mobile communication (GSM) came into existence. GSM was first deployed by Europe, this enabled services throughout Europe by means of international roaming. GSM provide services like short message service (SMS), picture message and MMS. Through this technology all text messages were digitally encrypted due to which only the intended receiver receives the message. These digital signals consume less battery power, so it helps in saving the battery power of mobile[1]. In GSM main elements are BTS (Base Transceiver Station), BSC (Base Station Controller) and NSS (Network Switching Subsystem) in which there are a MSC (Mobile Switching Centre), VLR (Visitor location Register), HLR (home Location Register), AC (Authentication Centre) and EIR (Equipment Identity Register). It is capable of providing all the basic services upto 9.6kbps, fax etc. In $2 \mathrm{G}$ main attention was devoted to interoperability and standardization. With the enhancement of MSC design, handoff mechanism was introduced. As the requirement for sending data on the air-interface increased, GPRS (General Packet Radio Services) came into existence. This GPRS added new elements such as SGSN (Servicing GPRS) and GGSN (Gateway GPRS) in existing GSM system. These elements of GPRS possible to send packet data on the air-interface, this part of network handling the packet data is called the packet data core network. GPRS also contains IP routers, DNS (Domain Name Server) and firewall servers. GPRS is a radio technology for GSM network which adds packet-switching-protocol, this make it possible to charge by the amount of data sent rather than connection time. Through packet switching, data is sent in the form of packets and then it is routed to the destination based on the address within each packet. GPRS is the most significant step towards $3 \mathrm{G}$ and it is scenario that is used in $2.5 \mathrm{G}$ which act as a bridge between $2 \mathrm{G}$ and $3 \mathrm{G}$. Beside GPRS 2.5G also contain some other technologies such as HSCSD (High Speed Circuit Switched Data), EDGE (Enhanced Data Rates for Global Evolution), these upgrades $2 \mathrm{G}$ network to make the existence of $3 \mathrm{G}$ possible[1,2,4].

Low power consumption, better security and better bandwidth usage are the advantages over its precedent technologies. 2G supported a large number of calls in the same radio bandwidth and ensures lower power consumption that improved battery life in mobile phones. $2 \mathrm{G}$ introduced digital encryption method for better security and privacy. GPRS makes mobile data access faster and cheaper, offers continuous connectivity and access to online services. Addition of EDGE in GSM help in increasing the data rate and this is done by using more sophisticated coding method over the internet which increased the data rate upto $384 \mathrm{Kbps}$ [5]. Difference of $1 \mathrm{G}$ and $2 \mathrm{G}$ is shown in table 1.

Table 1 . Difference between $1 G$ and $2 G$

\begin{tabular}{|l|l|}
\hline \multicolumn{1}{|c|}{$\mathbf{1 G}$} & \multicolumn{1}{c|}{$\mathbf{2 G}$} \\
\hline $\begin{array}{l}\text { It is analogue based i.e. it } \\
\text { transfer voice in analog wave. }\end{array}$ & $\begin{array}{l}\text { It introduced Digital } \\
\text { standards i.e. it convert } \\
\text { voice into digital code and } \\
\text { then into signal. }\end{array}$ \\
\hline $\begin{array}{l}\text { Technologies: AMPS, NMT, } \\
\text { CDPA }\end{array}$ & $\begin{array}{l}\text { Technologies: GSM, } \\
\text { CDMA, TDMA etc. }\end{array}$ \\
\hline It only support voice calls & $\begin{array}{l}\text { It support data along with } \\
\text { voice calls }\end{array}$ \\
\hline No concept of multiplexing & $\begin{array}{l}\text { Allow multiple users on } \\
\text { single channel via } \\
\text { multiplexing. }\end{array}$ \\
\hline No encryption & $\begin{array}{l}\text { Data send through network } \\
\text { in an encrypted form to } \\
\text { provide privacy }\end{array}$ \\
\hline $\begin{array}{l}\text { Limited network availability } \\
\text { (within the country) }\end{array}$ & $\begin{array}{l}\text { More coverage and capacity } \\
\text { (connecting all over the } \\
\text { world ) }\end{array}$ \\
\hline Data speed is 5-9 Kbps & Data speed is 9.6-30 Kbps \\
\hline
\end{tabular}

\subsection{Third Generation (3G)}

In 2000, $3 \mathrm{G}$ enters in the world of wireless mobile communication. EDGE make high-volume movement of data possible, but packet transfer on the air interface still behaves as circuits switch call. It was decided to have a network which serve services that are independent of technology platform and whose network design standards are same globally ${ }^{[1]}$. Besides these reasons in response to the subscriber growth and demand for data services that require high speed access, 3G came into existence. IMT-200 standards for 3G were defined by the International Telecommunication Union (ITU). Third Generation Partnership Project (3GPP) in an organization that has continued that work by defining a mobile system that fulfill the IMT-200 standards.in Europe it was called UMTS (Universal Terrestrial Mobile System) and CDMA is the name of the American $3 \mathrm{G}$ variant. This offers video calls, mobile TV, Location-based services and internet browsing at faster speed. It also provides variable transfer speed ranging between $128 \mathrm{Kbps}$ and $3 \mathrm{Mbps}$ depending on the speed with which mobile device is moving within the network. 3G also provides users with better security. Additional features of 3G upgradation are HSPA (High Speed Packet Access) which helps to improve performance of UMTS. It uses improved modulation scheme which refining the protocols that mobile devices and base station use to communicate. HSDPA (High Speed Downlink Packet Access) and (High Speed Uplink Packet Access) are 14.4 Mbps and 5.76 Mbps respectively. HSPA+ (High Speed Packet Access) which is able to deliver speeds up to $11.5 \mathrm{Mbps}$ and the downlink and 2.8 Mbps on the uplink. IMT-200 standards define the following characteristics for $3 \mathrm{G}$ system:

- Used worldwide

- Used for all mobile application

- Support both packet-switched and circuit switched data transmission 
- Offer high data rates up to $2 \mathrm{Mbps}$ (depending on mobility)

- Offers high spectrum efficiency

Beyond mobile telephony, the higher speed allowed 3G connection in PC's, gaming consoles, tablets and other portable devices that provide higher quality internet connection.

2.3.1 CDMA2000 1xEv-DO: Introduced high speed , packet switch technique for data transmission which enables peak data rate beyond 2 Mbps. 1xEV-DO was initially released as Release 0 (Rel. 0) and then its upgrade known as 1xEV-DO Revision A (Rev. A)

2.3.2 CDMA2000 1xEV-DO Rel. 0: It provides peak speed up to $2.3 \mathrm{Mbps}$ with an average user throughput of between $400 \mathrm{Kbps}$ and $100 \mathrm{kbps}$. Rel. 0 makes use of existing internet protocols enabling it t support IP base connectivity and Software application. It provides services like music, video, downloads, gaming and television broadcasts.

2.3.3 CDMA2000 $1 x E V-D O R e v$. A: It supports the framework which offers quality of services (QOS) application, reduce latency. It provides services such as ability to send large files, email attachments, pictures and video from mobile devices. Average speeds of Rev. A are 600 to 1400 Kbps for downloads and 500 to $800 \mathrm{Kbps}$ for uploads. And peak speeds of 3.1 Mbps for download and 500 to $800 \mathrm{Kbps}$ for upload [6].

$3 \mathrm{G}$ network was delayed in same countries because of various reasons such as in many countries $3 \mathrm{G}$ network do not use the same radio frequencies as $2 \mathrm{G}$, so building an entirely new network and license entirely new frequencies were the biggest issues. Beside these Licensing fees in some European countries were extremely high, other delays were due to the expense of upgrading equipment for the new system. United State is the exception of some of these reasons as there carrier operates $3 \mathrm{G}$ services in the same frequencies as other services. But $3 \mathrm{G}$ technology is much more flexible as it can support major radio technologies that operate under CDMA, TDMA and FDMA. The main aim of this technology is to allow much better coverage and growth with minimum investment [11]. Difference of $2 \mathrm{G}$ and $3 \mathrm{G}$ is shown in table 2 .

Table 2 . Difference between 2G and 3G

\begin{tabular}{|l|l|}
\hline \multicolumn{1}{|c|}{ 2G } & \multicolumn{1}{|c|}{ 3G } \\
\hline $\begin{array}{l}\text { Digital narrow band Circuit } \\
\text { data and Packet data }\end{array}$ & $\begin{array}{l}\text { Digital Broadband Packet } \\
\text { data }\end{array}$ \\
\hline $\begin{array}{l}\text { Comparatively slow speed } \\
\text { than 3G }\end{array}$ & $\begin{array}{l}\text { Support much higher } \\
\text { throughput and speed than } \\
2 \mathrm{G}\end{array}$ \\
\hline $\begin{array}{l}\text { Data services such as SMS, } \\
\text { MMS, internet access and } \\
\text { SIM cards }\end{array}$ & $\begin{array}{l}\text { Introduced term Mobile } \\
\text { Broadband because of its } \\
\text { speed and capability , also } \\
\text { provide universal access and } \\
\text { portability across different } \\
\text { device types }\end{array}$ \\
\hline $\begin{array}{l}\text { Speed : 9.6-30 Kbps } \\
\text { Frequency band: Initially 900 Mbps } \\
\text { MHz spectrum was used but } \\
\text { later GSM introduced 1800 }\end{array}$ & $\begin{array}{l}\text { Speed } \\
\text { (peak)/500-700 Kbps }\end{array}$ \\
\hline
\end{tabular}

\begin{tabular}{|l|l|}
\hline MHz band & \\
\hline $\begin{array}{l}\text { Technologies: GSM with } \\
\text { technological backbone of } \\
\text { TDMA }\end{array}$ & $\begin{array}{l}\text { Technologies: UMTS as its } \\
\text { core network architecture } \\
\text { with HSPA protocol }\end{array}$ \\
\hline $\begin{array}{l}\text { Voice and data cannot be } \\
\text { simultaneously supported }\end{array}$ & $\begin{array}{l}\text { Simultaneously voice and } \\
\text { data supported }\end{array}$ \\
\hline $\begin{array}{l}\text { It consist of only circuit } \\
\text { switched network }\end{array}$ & $\begin{array}{l}\text { It uses combination of both } \\
\text { circuit switched and packet } \\
\text { switched }\end{array}$ \\
\hline
\end{tabular}

\subsection{Long Term Evolution (LTE)}

Although $3 \mathrm{G}$ technologies deliver significantly higher bit rate than $2 \mathrm{G}$, there is still more opportunities for wireless operators to fulfill the ever changing demand of wireless broadband such as low latency and multi-megabit throughput. The solution for this is Long Term Evolution (LTE), a Third Generation Partnership Project (3GPP) standards that provides much greater spectral efficiency that the most advanced $3 \mathrm{G}$ network [7]. Migration of $2 \mathrm{G}$ to LTE is shown in fig. 1[7].

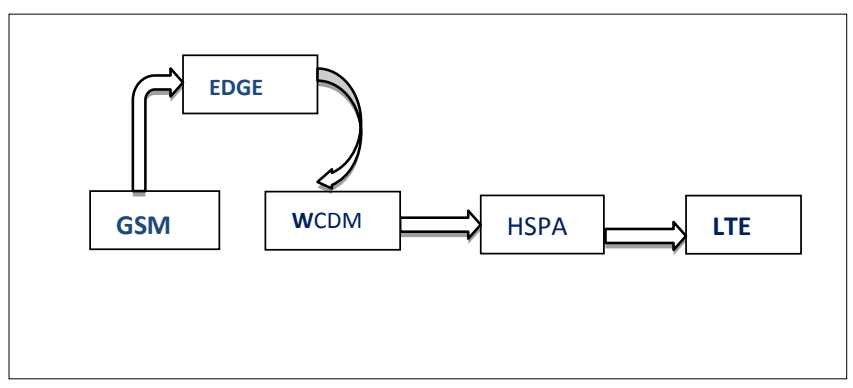

Fig. 1 Migration of wireless broadband

LTE is designed to provide multi-megabit bandwidth, more efficient use of radio network, latency reduction and improved quality. Changes in mobile communication have always been evolutionary and the deployment of LTE will be the same. LTE is the transition from $3 \mathrm{G}$ to $4 \mathrm{G}$, as we are still in the stage of transition from $2 \mathrm{Gto} 3 \mathrm{G}$. As a result mobile operators must look for strategies and solution that enhance their existing $2 \mathrm{G}$ and $3 \mathrm{G}$ network towards $4 \mathrm{G}$ without requiring a complete equipment upgradation. LTE is a solution for this upgradation which is based on new radio access network called OFDM (Orthogonal Frequency Division Multiplexing) technology. Release 8 of 3GPP specified the air-interface for LTE which combines OFDMA base modulation and multiple access schemes for the downlink with SC-FDMA (Single Carrier FDMA) for the uplink. OFDM scheme split available spectrum into thousands of extremely narrowband carriers each carrying a part of the signal and further enhanced with higher order modulation and sophisticated FEC (Forward Error correction) scheme. The result of these radio interface feature is significantly improved radio interface features is significantly improved radio performance yielding up to 5times the average throughput of HSPA [9]. Uplink Downlink rates compared for HSPA and LTE shown in fig 2 [9]. 


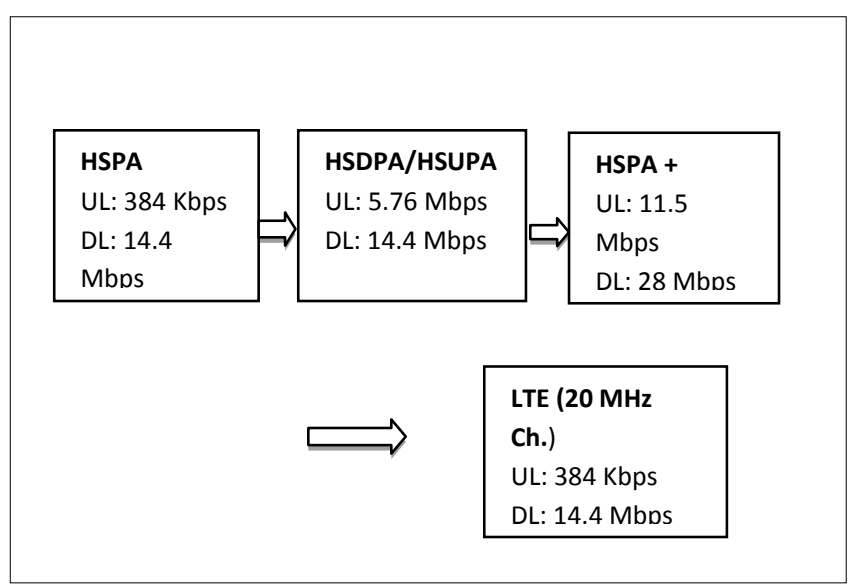

Fig. 2 Uplink Downlink rates compared for HSPA and LTE

The multimedia are network of LTE will pay a central role in service control and a smooth migration from $3 \mathrm{G}$ to 4 . This is the multimedia core network which meets the requirements of System Architecture Evolution (SAE), the 4G core architecture of the LTE standards. SAE calls for a transition to a flat, all IP core network called Evolved Packet Core (EPC), which features a simplified architecture and open interfaces as defined by the 3GPP standard body. EPC enables operates to launch services and application with internet speed while also reducing the overall cost per packet. EPC also able to address divergent mobility management problem. It supports all access technologies, including $2 \mathrm{G}, 3 \mathrm{G}$, and $4 \mathrm{G}$ from all the Mobility management Entity (MME), Servicing Gateway (SGW) and Packet Data Network Gateway (PGW) as specific network function, these three functions can logically be integrated into one node [7].

\subsubsection{Key consideration of LTE is [7,9]:}

- Integration of intelligence at the access edge: this intelligence includes quality of services (QOS) and policy enforcement.

- Simplified network topology: in order to deliver the enhanced performance of LTE effectively, the network need to be simplified and patterned, by reducing the elements involve in data processing and transport.

- Converged mobility and policy: maintain the subscriber session is an important consideration during $4 \mathrm{G}$ to $2 \mathrm{G}$ or $4 \mathrm{G}$ to $3 \mathrm{G}$ mobility events enhancing mobility, efficient use of network resources, standards-defining organization. EPC specification call out

- Increase performance characteristics.

- Migration from $2 \mathrm{G}$ to $4 \mathrm{G}$ or $3 \mathrm{G}$ to $4 \mathrm{G}$ : mobile operators needs to minimize costs to avoid a complete equipment upgrade while deploying solution based on open standards.

Solution designed for the specific requirements of the next generation multimedia core network include the capacity to support2G, 3G and $4 \mathrm{G}$ function in a single platform [7,9]. Difference of $3 \mathrm{G}$ and LTE is shown in table 3.

\subsubsection{Implication of LTE on mobile Transport:}

- High capacity at lower cost

- Multiservice transport

- Low latency and quality of services (QOS)

- Convergence of backhaul/backbone

- Increased connectivity and load sharing

- Re-configurability and network agility

- Accurate clock synchronization

- Security

Table 3. Difference between $3 G$ and LTE

\begin{tabular}{|l|l|}
\hline \multicolumn{1}{|c|}{ 3G } & \multicolumn{1}{|c|}{ LTE } \\
\hline $\begin{array}{l}\text { Comparatively less speed and } \\
\text { quality than LTE }\end{array}$ & $\begin{array}{l}\text { Support much more speed } \\
\text { and quality than 3G }\end{array}$ \\
\hline $\begin{array}{l}\text { Video calling and seamless } \\
\text { streaming of video possible } \\
\text { with download speed up to } \\
3.1 \mathrm{Mbps}\end{array}$ & $\begin{array}{l}\text { Support HD video } \\
\text { streaming, download speed } \\
\text { as high as 299.6 Mbps }\end{array}$ \\
\hline $\begin{array}{l}\text { Radio technology: Uses } \\
\text { TDMA, CDMA }\end{array}$ & $\begin{array}{l}\text { Radio technology: OFDM } \\
\text { (orthogonal FDMA) }\end{array}$ \\
\hline $\begin{array}{l}\text { Speed : 3.1 Mbps (peak)/500- } \\
700 \mathrm{Kbps}\end{array}$ & $\begin{array}{l}100-300 \mathrm{Mbps} \text { (peak)/ 3-5 } \\
\text { Mbps }\end{array}$ \\
\hline Frequency band : 1.8-2.5GHz & Frequency band : 2-8 GHz \\
\hline $\begin{array}{l}\text { UMTS and CDMA2000 } \\
\text { standards are used }\end{array}$ & $\begin{array}{l}\text { In this multiple radio } \\
\text { standards unified into a } \\
\text { single IP network }\end{array}$ \\
\hline $\begin{array}{l}\text { Simultaneously voice and } \\
\text { data supported }\end{array}$ & $\begin{array}{l}\text { Simultaneously voice and } \\
\text { data supported at higher } \\
\text { data rates than 3G }\end{array}$ \\
\hline $\begin{array}{l}\text { It uses combination of both } \\
\text { circuit switched and packet } \\
\text { switched }\end{array}$ & $\begin{array}{l}\text { Use only packet switched } \\
\text { network }\end{array}$ \\
\hline
\end{tabular}

Table 4 : Comparison between 1G 2G 3 G and LTE

\begin{tabular}{|l|l|l|l|l|}
\hline & \multicolumn{1}{|c|}{$\mathbf{1 G}$} & \multicolumn{1}{|c|}{ 2G } & \multicolumn{1}{|c|}{ 4G-LTE } \\
\hline Definition & Analogue based & $\begin{array}{l}\text { Digital narrow band } \\
\text { Circuit data and Packet } \\
\text { data }\end{array}$ & Digital Broadband Packet data & $\begin{array}{l}\text { Integration of intelligence at } \\
\text { the access edge include quality } \\
\text { of service }\end{array}$ \\
\hline Services & Voice calls only & $\begin{array}{l}\text { SMS, MMS, internet } \\
\text { access and SIM cards }\end{array}$ & $\begin{array}{l}\text { Video call, mobile TV, } \\
\text { location based service, } \\
\text { internet access at faster speed. } \\
\text { Universal access and } \\
\text { portability across different } \\
\text { device types }\end{array}$ & $\begin{array}{l}\text { High definition streaming,IPv6 } \\
\text { support and QOS }\end{array}$ \\
\hline
\end{tabular}




\begin{tabular}{|c|c|c|c|c|}
\hline $\begin{array}{l}\text { Radio } \\
\text { Technologies }\end{array}$ & None & CDMA, TDMA & CDMA, TDMA, FDMA & $\begin{array}{l}\text { OFDMA (Orthogonal FDMA), } \\
\text { SC-FDMA (Single Carrier } \\
\text { FDMA) }\end{array}$ \\
\hline $\begin{array}{l}\text { Throughput/ } \\
\text { Speed }\end{array}$ & $5.9 \mathrm{Kbps}$ & 9.6-30 Kbps & $\begin{array}{l}\text { 3.1 Mbps (peak)/500-700 } \\
\text { Kbps }\end{array}$ & $\begin{array}{l}\text { 100-300Mbps (peak)/ 3-5 } \\
\text { Mbps }\end{array}$ \\
\hline $\begin{array}{l}\text { Frequency } \\
\text { band }\end{array}$ & & $\begin{array}{l}\text { Initially } 900 \mathrm{MHz} \\
\text { spectrum was used but } \\
\text { later GSM introduced } \\
1800 \mathrm{MHz} \text { band }\end{array}$ & $1.8-2.5 \mathrm{GHz}$ & $2-8 \mathrm{GHz}$ \\
\hline Technologies & $\begin{array}{l}\text { AMPS,NMT,TAC } \\
\text { S,CDPA }\end{array}$ & $\begin{array}{l}\text { GSM with backbone of } \\
\text { TDMA }\end{array}$ & $\begin{array}{l}\text { UMTS as its core network } \\
\text { architecture with } \text { HSPA } \\
\text { protocols }\end{array}$ & $\begin{array}{l}\text { MIMO(multiple input and } \\
\text { multiple output) with backbone } \\
\text { f OFDMA and SC-FDMA }\end{array}$ \\
\hline Standards & Analogue & $\begin{array}{l}\text { GSM, GPRS }(2.5 \mathrm{G}), \\
\operatorname{EDGE}(2.75 \mathrm{G})\end{array}$ & $\begin{array}{l}\text { UMTS and CDMA2000 } \\
\text { standards }\end{array}$ & $\begin{array}{l}\text { Multiple radio standard unified } \\
\text { into a single IP network }\end{array}$ \\
\hline $\begin{array}{l}\text { Voice and } \\
\text { data support }\end{array}$ & Voice support only & $\begin{array}{l}\text { Voice and data cannot } \\
\text { be simultaneously } \\
\text { supported }\end{array}$ & $\begin{array}{l}\text { Simultaneously voice and data } \\
\text { supported }\end{array}$ & $\begin{array}{l}\text { Simultaneously voice and data } \\
\text { supported at higher data rates } \\
\text { than } 3 \mathrm{G}\end{array}$ \\
\hline $\begin{array}{l}\text { Switching } \\
\text { technique }\end{array}$ & None & $\begin{array}{l}\text { circuit switched } \\
\text { network }\end{array}$ & $\begin{array}{l}\text { circuit switched and packet } \\
\text { switched network }\end{array}$ & $\begin{array}{l}\text { Use only packet switched } \\
\text { network, thus lowering latency } \\
\text { and enhancing access quality }\end{array}$ \\
\hline
\end{tabular}

\section{ISSUES AND CHALLENGES OF LTE}

- $\quad$ Lack in providing traditional services: biggest issue of LTE is that it is lack in supporting of traditional services such as voice calls, text messages, multimedia messaging etc. Due to which LTE cannot replace current $2 \mathrm{G}$ and $3 \mathrm{G}$ network. Recently solution of this problem is proposed by adding VoLTE (Voice over LTE) but further research is continues to overcome other difficulties relate to traditional services in LTE.

- LTE Roaming Issue: LTE global roaming is impossible because of LTE spectrum bands which don't match across different countries.

- Migration of 3G to LTE: Cost is the major issue in migration of $3 \mathrm{G}$ in LTE. Currently, commercial services are available from the most wireless carriers and these commercial services charge on monthly basis which prove costly for large agencies. Commercial networks are not built to be- mission critical. Tower sites are built without taking care to protect the network components, and without generators, to make them sustainable at the line of long power failure [13].

- Handover calls from $3 \mathrm{G}$ to LTE and vice-versa is an issue in using LTE.

- Battery life: LTE consumes more battery in LTEenable devices due to its high bandwidth technology [13].

\section{CONCLUSION}

In this paper the evolution of various generations of wireless mobile communication is provided. Overview of services, technologies, standards of $1 \mathrm{G}, 2 \mathrm{G}, 3 \mathrm{G}$ and LTE were discussed. Comparison of LTE (which is current technology of mobile wireless) with their preceding technologies are given. It also highlights few potential issues and challenges of LTE. In order to achieve the complete implementation of LTE we should promote further research and innovation to meet the issues and challenges of LTE.

In this literature study we have identified few major issues and challenges of LTE. More research work needs to be done to overcome these limitations. We shall do further research and find out some solution to resolve the issues related to security and battery life.

\section{REFERENCES}

[1] Kumar, A., Liu, Y., Sengupta, J., Divya 2010 Evolution of mobile wireless communication networks: $1 \mathrm{G}$ to $4 \mathrm{G}$. Nanjang Forestery university, Nanjing, China,IJECT vol.1,Issue 1,December.

[2] Nabeel ur Rehman, Asif, A., Iqbal, J. 2006. 3G Mobile communication networks. National University of sciences and technology, Pakistal unpublished.

[3] White paper, LTE Networks: Evolution and Tecnology Overview. Dialogic, Tektronix communication.

[4] Mohammed Jaloun and Guennoun, Z, Wireless mobile evolution to $4 \mathrm{G}$ networks. Wireless sensor network, 2010, 2,309-317.

[5] Paper "2G and 3G mobile Communication",Irunway, 2013 
[6] LTE White paper, "LTE: The future of mobile broadband technology," verizon.

[7] White paper, "Long-term evolution: simplify the migration to 4G networks" CISCO.

[8] Article "LTE services and implication".

[9] White paper, 2008. "Towards global mobile broadband",UMTS, February.

[10] White paper, 2009 "Long-term evolution: The vision beyond 3G”,IEEE communication magazine, april.
[11] " $3 \mathrm{G}$ and LTE", www.engineeringgarage.com, [last access] 13,11 2013

[12] Bilogrevic, I., Jadliwala, M. and Hubaux, J.P. Security issues in next generation mobile networks: LTE and femtocells. EPFL, Lausanne, Switzerland

[13] White Paper "The Five Myths of LTE Optimization", flash networks

[14] Jimaa, S. LTE-A an Overview and future research areas. Khalifa University, UAE. 